\title{
EVALUATING DISABILITY MANAGEMENT IN THE MANITOBAN CONSTRUCTION INDUSTRY FOR INJURED WORKERS RETURNING TO THE WORKPLACE WITH A DISABILITY
}

J. Winter ${ }^{1}$, M. H. Issa ${ }^{2}$, R. Quaigrain ${ }^{3}$, K. Dick ${ }^{4}$ and J. D. Regehr ${ }^{5}$

${ }^{1}$ Graduate Student

Department of Civil Engineering, University of Manitoba

15 Gillson Street, Winnipeg, Manitoba, Canada, R3T 5V6

Email: winterj@myumanitoba.ca

${ }^{2}$ Assistant Professor

Department of Civil Engineering, University of Manitoba

15 Gillson Street, Winnipeg, Manitoba, Canada, R3T 5V6

Tel.: (204) 474-8786, Fax: (204) 474-7513

Email: Mohamed.Issa@umanitoba.ca

${ }^{3}$ Graduate Student

Department of Civil Engineering, University of Manitoba

15 Gillson Street, Winnipeg, Manitoba, Canada, R3T 5V6

Email: quaigrainr@umanitoba.ca

\footnotetext{
${ }^{4}$ Associate Professor
} 
Department of Biosystems Engineering, University of Manitoba

15 Gillson Street, Winnipeg, Manitoba, Canada, R3T 5V6

Tel.: (204) 474-6457, Fax: (204) 474-7512

E-mail: Kristopher.Dick@umanitoba.ca

${ }^{5}$ Assistant Professor

Department of Civil Engineering, University of Manitoba

15 Gillson Street, Winnipeg, Manitoba, Canada, R3T 5V6

Tel.: (204) 474-8779, Fax: (204) 474-7513

E-mail: Jonathan.Regehr@umanitoba.ca 
ABSTRACT: The poor safety record of the construction industry raises concerns about the extent to which it is able to integrate workers disabled as a result of a workplace injury back to the workplace. A review of the literature indicates there is little empirical evidence about the status of disability management (DM) in the Canadian construction industry, specifically with respect to injured construction workers returning to the workplace with a disability. To address this limitation, a web-based survey was administered to a sample of Manitoban construction organizations to enquire about workers disabled as a result of a workplace injury in the industry, practices in place to accommodate them, and barriers to their employment. The analysis of the responses of 88 organizations showed that the majority of responding organizations employed few disabled workers. Disabilities due to musculoskeletal injuries (MSI) were the most common, followed by physical mobility and hearing impairments. Respondents saw retaining valued and experienced employees and maintaining employee morale as the main reasons for implementing a DM program. They also found the lack of suitable modified or alternate work to be the most important barrier to DM; however, they identified the provision of such work as the most common practice implemented by them, raising questions about this work's suitability to disabled workers.

Keywords: construction, disability management, disabled workers, return to work programs.

Word Count: 7,155

Figures: 0

Tables: 7 


\section{INTRODUCTION}

The construction industry has traditionally had a poor safety record. A review of the literature shows that in certain industrialized nations, the industry has a fatal and major injury rate that is three times higher than that of all other industries (Clarke et al. 2009). Lingard \& Saunders (2004) found that only 57\% of construction workers reached the age of 65 without suffering a permanent impairment. Clarke et al. (2009) estimated the rate of unreported accidents at 50\% and found that $62 \%$ of construction workplaces had unsafe conditions and $46 \%$ of the construction workforce had the training required to do their jobs.

In Canada, the construction industry was responsible for 27,577 time-loss injuries in 2012, representing the third highest number of time-loss injuries behind the health and social service and manufacturing industries for that year (Association of Workers' Compensation Boards of Canada 2013). It was responsible for a total of 211 fatalities in 2012, representing $21.6 \%$ of all fatalities alone: the highest rate of any industry in the country.

In Manitoba, the construction industry was responsible in 2012 for 2,082 time-loss injuries and also had the third highest rate of time-loss injuries in 2012. Six fatalities related to the construction industry were reported in 2012. These represented $16.7 \%$ of all fatalities in Manitoba: the second highest rate behind government services in 2012 (Association of Workers' Compensation Board of Canada 2013). This is despite the construction industry representing only 7.2\% of the total workforce in Manitoba in 2012. Despite a decrease in heavy and building construction's time loss injury rates from $11 \%$ and $7.5 \%$ in 2000 to $6.4 \%$ and $4.5 \%$ in 2012 respectively, these rates are still higher than the 3.3\% average rate for all major industries in 2012 
(Workplace Safety and Health Division of Manitoba 2013 and Association of Workers' Compensation Board of Manitoba 2013).

These statistics raise concerns about the extent to which the industry is able to successfully integrate injured workers back into the workforce. This is a concern given how some construction employers still believe that disabled people do not have a place in the industry (Newton and Ormerod 2005, Tshobotlwane 2005). Furthermore, most employers do not seem to have formal policies and procedures in place to support returning disabled people and are only ready to comply with existing legislation provided adjustments to do so are minor and inexpensive (Tshobotwane 2005, Newton and Omerod 2005).

A review of the literature reveals little empirical evidence about the status of disability management (DM) in the Canadian construction industry, specifically with respect to injured construction workers returning to the workplace with a disability. Therefore, this research aims to evaluate DM in the Canadian construction industry, focusing on injured workers returning to the workplace with a disability. Specific objectives include:

1. Investigating the status of injured workers returning to the workplace with a disability

2. Investigating barriers to their return

3. Assessing DM programs, practices, incentives and accommodations in place to support their return

This research focused on DM in the Manitoban construction industry specifically, addressing this aspect from the employer's rather than the employee's perspective. The research evaluated the 
perception of various construction employers including electrical, general, mechanical, and trade contractors.

The significance and originality of this research stem from its focus on construction workers disabled as a result of workplace injury in Canada, making it one of the first research studies to focus on DM in the Canadian construction industry specifically. The research contributes to a better understanding of the state of DM in the Manitoban construction industry in particular. It enables an understanding of the extent to which DM programs are implemented in Manitoba, and an identification of the barriers to the return of disabled workers to the workplace, their specific disabilities, and the practices and accommodations in place to support them. This should make the research relevant to construction management researchers interested in improving the performance of the industry and ensuring the safe return of injured workers back to the workplace. It should also make it relevant to construction employers looking to improve their DM practices as well as policy-makers aiming to improve existing guidance in the field to better protect the rights of injured workers returning to the workplace.

A review of the literature reveals a lack of research studies on DM in Canada's construction industry, and on the topic of DM in construction in general. The few studies that have conducted such research have focused on DM in the British (UK) (e.g. Newton and Ormerod 2005) South African (e.g. Tshobotlwane 2005) and Australian (e.g. Lingard and Saunders 2004) construction industries. Existing studies in the field (e.g. Ormerod and Newton 2013, Tshobotlwane 2005) seem to have also focused on the employment of disabled workers in general which includes workers entering the industry with a disability. Only one study (e.g. Lingard and Saunders 2004) 
seems to have focused exclusively on workers disabled as a result of injuries sustained in the construction workplace and the accommodations and practices in place to ensure their return.

\section{LITERATURE REVIEW}

This section includes definitions of a number of key terms used throughout the paper before reviewing existing guidance on DM in Canada and Manitoba. It concludes with a review of the literature focusing on DM in construction in particular.

\subsection{Definitions and Overview of Disability Management}

The term "Disability" can be defined in a number of ways. The World Health Organization uses three terms to describe it: "Impairments", "Activity Limitations" and "Participation Restrictions" (WHO 2014). "Impairments" are problems related to body function or structure. "Activity Limitations" relate to people who have difficulty in executing tasks or actions whereas "Participation Restrictions" are problems individual encounter when getting involved in life situations (WHO 2014). This research limited the definition of "Disability" to the term "Impairments" used by the WHO (2014) and did not therefore include the terms "Activity Limitations" and "Participation Restrictions" as part of its definition.

Ormerod and Newton (2006) define "Disability" as a feature that certain people carry whose minds, bodies or senses appear to be different due to mobility, sensory, cognition or psychological impairments. The size, shape and appearance of such disability can also vary from person to person. The Individual or Medical Model makes use of this definition (Ormerod and Newton 2006) whereas the Social Model assumes that society operates in a way that discriminates against people who do not meet the perceived norm and excludes them, thus 
disabling them. The model argues that any person can become disabled at any point in time. For example, a person pushing a stroller can become disabled by stairs or narrow doorways. A ramp would remove such disability. Clarke et al. (2009) argue that what might be a disability for one occupation may not be disabling for, citing dyslexia as an example. Dyslexia is not problematic for most construction workers yet colour blindness can be to electricians and other construction trades, making disability relative and dependent on the occupation and work undertaken (Clarke et al. 2009).

Clarke et al. (2009) adopt the Disability Discrimination Act (DDA) definition of "Disability". DDA defines a disabled person as someone who has a long-lasting physical, including sensory or mental health condition or disability that can last for 12 months and that can have a substantial effect on the person's ability to carry out normal day-to-day activities (Ormerod and Newton 2013). Similarly, Tshobotlwane (2005) describes a disabled person as an individual who is unable to use a part of their body completely or easily due to a physical condition, illnesses or injury.

Two other key terms are used throughout this paper: "Disability Management" (DM) and "Return to Work" (RTW). DM aims to manage absences from work caused by illnesses, injuries or disabilities, and risk prevention leading to these absences (Treasury Board of Canada Secretariat 2011b). It does so by preventing disability from occurring and encouraging and supporting continued employment should it occur. The concept was developed by employers to control disability costs beginning in the mid-1980's (Galvin et al. 1986). The concept built on older vocational rehabilitation programs for injured workers and gradually evolved to incorporate the RTW model. As regulations became more stringent, aspects such as safety, ergonomics, ecological assessment and specialized case management strategies were integrated into it (Hursh 
1997, Rosenthal et al. 2005). Over time, the service-based approach evolved to a workplace based approach and took into account aspects such as organizational development, safety, risk management, and case management (Rosenthal, et al. 2007). These aspects became the foundations of DM policies and programs. DM in essence incorporates three key domains: prevention, early intervention and proactive RTW interventions to reduce the impact of injury and disability and to accommodate those experiencing functional work limitations.

The term "Return to Work (RTW)" is usually used in conjunction with "Programs" and refers to the tools employers use to proactively help ill or injured workers stay on the job or return to productive employment in a timely and safe manner (Treasury Board of Canada Secretariat 2011a). They are the tools employers use to manage disability. RTW programs can help employees perform productive work during their recovery period by providing them with modified and alternate work (Workers Compensation Board of Manitoba 2000). Modified work is offered when a worker is able to return to work yet unable to resume his or her pre-accident job duties without assistance or support (Workers Compensation Board of Manitoba 2000). This results in the employer modifying their former jobs by revising their tasks, functions, hours of work, work site, or any combination of these. Modified work can also encompass gradual return to work, where the worker temporarily works for limited hours or limited duties as part of a plan leading to full employment once recovered (Workers Compensation Board of Manitoba 2000). Alternate work is offered when the worker is temporarily or permanently unable to perform his or her pre-accident job (Workers Compensation Board of Manitoba 2000). A different job or position than the one performed by the worker prior to the injury is then offered. Another form of alternate work is transitional work, where the worker is temporarily employed in a different position or job leading to full employment (Workers Compensation Board of Manitoba 2000). 


\subsection{Guidance on Disability Management in Canada}

In response to discrimination in the labour market against people with disabilities, several countries have enacted legislation such as the Americans with Disabilities Act and the UK Disability Discrimination Act to protect their rights. Although Canada does not have separate legislation to protect their rights (Shrey and Hursh 1999), two pieces of legislation have been introduced at the federal level over the last few years: the Canadian Charter of Human Rights and the Duty to Accommodate. These require employers to provide reasonable accommodation to workers to enable them to do their jobs. However, these regulations also have "undue hardship" clauses that can circumvent this obligation. Additionally, Canada has invested heavily at the federal and provincial levels in the development of training programmes for DM, with the goal of creating safer work environments that accommodate employees with disabilities (Organization for Economic Cooperation and Development 2010). An example includes the Targeted Wage Subsidies Programme, designed to encourage employers to hire employees with disabilities by temporarily subsidizing up to $100 \%$ of their wages to address their workplace accommodation needs (Organization for Economic Cooperation and Development 2010). Although Canada does have human rights laws forbidding discrimination based on disability, this has not transpired into a federal disability act, resulting in very little progress for Canada, particularly regarding employment equity. Only three out of ten provinces have their own disability legislation: Ontario's Accessibility for Ontarians with Disabilities Act (Government of Ontario 2001 2005), Nova Scotia's Community ACCESS-Ability Program (Government of Nova Scotia 2005) and Manitoba's Accessibility Act (2013). 
A major proponent in monitoring and regulating DM practices in the Canadian workplace includes the Workers Compensation Acts enacted in every province and their regulating bodies. In Canada, workers compensation is managed by Workers Compensation Boards operating under provincial regulation (OECD 2010). Federal employees who are not under provincial jurisdiction are covered by the Federal Government Employees Compensation Act. The aim of these acts is to provide compensation to injured workers regardless of fault, ensure their timely and safe return to work and prevent workplace injuries. Premiums are paid by employers to an "Accident Fund" and rated according to industry classes and occupations, and individual employer's experiences. Under the Workers Compensation Act and Occupational Health \& Safety Regulations, employers are responsible for short and long-term disability benefits to employees who experience workrelated injuries and illnesses. Premiums accumulated are directed towards providing medical and rehabilitation aid, supplementing lost wages to injured workers and paying for board administration fees.

\subsection{Disability Management in Construction}

Research on DM in construction is still in its early stages, and thus very little published work is available on the topic. The published work focused on the UK (Newton and Ormerod 2005, Ormerod and Newton 2013), South African (Tshobotlwane 2005, Smallwood and Haupt 2008) and Australian (Lingard and Saunders 2004) construction industries in particular. The work also focused on investigating the status of disabled workers in general, and more specifically on workers entering the industry with a disability. The only study to have focused on returning injured workers (Lingard and Saunders 2004) focused on evaluating the extent to which formal RTW programs were implemented and impediments to that implementation, with no evaluation of the specific practices, accommodations and resources in place to support that implementation. 
The study showed how the nature of the industry was such that many construction workers did not have a long-term relationship with their employers; compounding the unwillingness of employers to accommodate them should they get injured (Lingard and Saunders 2004). Small construction firms were also less able to accommodate injured workers than larger ones because they are less likely to have the resources to do so (Lingard and Saunders 2004). Construction firms found DM to have increased their operating costs with negligible benefits in terms of worker output. Additionally, firms were reluctant to adopt and implement formal rehabilitation and RTW programs because of the difficulty with providing suitable alternate work for disabled persons.

Studies investigating the employment of disabled workers in the construction industry showed how many employers believed that people with disabilities do not have a place in the construction industry (Newton \& Ormerod 2005, Tshobotlwane 2005), with new entrants facing more challenges than returning ones. This is because employers were less likely to recruit people with disabilities than take back ones disabled because of an injury on the job (Newton \& Ormerod 2005). Most employers also had little to no formal practices in place to support construction workers with disabilities and were ready to comply with existing legislation only when adjustments to do so were minor and inexpensive (Tshobotwane's 2005, Newton and Omerod 2005). Construction employers were also less likely to have such policies and practices than employers in other industries (Newton and Ormerod 2005). Tshoboltwane's (2005) survey found that employers who had complied with the act found the cost to do so negligible. A later study by Omerod and Newton (2013) using interviews and mini focus groups to investigate barriers to the employment of young people with disabilities in the UK construction industry, revealed the need for inclusive approaches that would treat workers with disabilities equally rather than favourably. 
The industry, including both employers and professional institutions, also needed to raise awareness on the range and scope of opportunities available for young workers with disabilities to dispel the myths that construction work is only for able-bodied, fit men. Another study by Smallwood and Haupt (2008), also investigating the employment of disabled workers in general in the industry, recommended that governments provide incentives to encourage the employment of people with disabilities.

Despite these recommendations, the traditional perception that construction is a physically demanding job that makes it challenging to people with disabilities persists (Lingard and Saunders 2004, Tshobotlwane 2005). Some jobs automatically excluded by employers are those found in a typical construction environment. They include "ladder climbing, walking on rough terrain, tunnelling, working at height, working in confined spaces and working on the railways" (Newton and Ormerod 2005). Disabled people are usually found to be more suited for officebased design, management or administrative roles (Lingard and Saunders 2004). Smallwood \& Haupt (2008) found disabled people usually more suited to "on-site administrative functions, onsite auxiliary services, and off-site functions than on-site supervision, site management, and production".

A review of the six journal articles (Clarke et al. 2009, Dainty et al. 2004, Smallwood and Haupt 2008, Lingard and Saunders 2004, Newton and Ormerod 2005, Ormerod and Newton 2013), and dissertation (Tshobotlwane 2005) focusing on DM in the construction industry showed how none of the studies reported in these publications were conducted in Canada. With respect to the methods used in these studies, one study (Dainty et al. 2004) used interviews, two (Smallwood and Haupt 2008, Lingard and Saunders 2004) employed surveys and the fourth (Ormerod \& 
Newton 2013) conducted a participatory research. The fifth (Newton \& Ormerod 2005) used a survey and complemented it with case studies and interviews, whereas the last one (Clarke et al. 2009) analyzed a case study. This research adopted a quantitative approach similar to some of these studies.

\section{RESEARCH METHODOLOGY}

Because of its need to investigate the perception of a relatively large number of companies, this research involved designing and administrating a web-based anonymous survey to construction companies in Manitoba through the Construction Safety Association of Manitoba (CSAM). The survey contained 18 questions: 17 closed-ended quantitative questions and only one open-ended qualitative one. The majority were closed-ended because these questions were usually quicker to answer and simpler to deal with. One open-ended question was added to enable respondents to articulate their views and address aspects not covered by closed-ended questions. Furthermore, where appropriate, closed-ended questions included an "Other: please specify" option to give respondents an opportunity to add to the options offered by the actual questionnaire. Table 1 summarizes the design and content of the questionnaire. As shown in Table 1, the questionnaire enquired about the type of organizations respondents worked in, their role within the organization and the type of work their organization did. The questionnaire also enquired about whether their organization was certified according to the Certificate of Recognition Program (COR), the number of employees within their organizations and the percentage of disabled employees within them. Respondents were asked to rank the most common disabilities found in their organizations as a result of workplace injuries, barriers to the successful return of disabled workers following a

work injury and reasons why construction organizations should have DM and RTW programs. The questionnaire enquired about responding organizations' implementation of a DM program 
and the specific practices, accommodations and resources used as part of these programs. Responding organizations were also asked to indicate their level of agreement or disagreement with a number of conclusions derived from the literature in the context of injured disabled workers returning to the workplace. They were asked about their perception of financial incentives aimed at encouraging the adoption of DM programs and their awareness of the WCB's role.

Table 1: Design and Content of Survey Questionnaire

\begin{tabular}{|c|c|c|}
\hline Question Numbers & Question Types & Issues Investigated \\
\hline Questions $1-4$ & Multiple choice & Demographics of responding organization \\
\hline Questions 5-6 & Multiple choice & $\begin{array}{l}\text { Size of organization and organization's } \\
\text { employment of disabled workers }\end{array}$ \\
\hline Questions 7-8 & Ranking & $\begin{array}{l}\text { Disabilities accommodated by organization, } \\
\text { barriers to return of disabled workers }\end{array}$ \\
\hline Questions 9-11 & $\begin{array}{l}\text { Ranking, } \\
\text { No }\end{array}$ & $\begin{array}{l}\text { Organization's implementation of DM program, } \\
\text { rationale for implementing DM program }\end{array}$ \\
\hline Questions $12-14$ & Multiple choice & $\begin{array}{l}\text { Practices, accommodations and resources used by } \\
\text { organization as part of DM program }\end{array}$ \\
\hline Que & Rating & Organization's perception of literature results \\
\hline Question $16-17$ & Yes/ No & $\begin{array}{l}\text { Organization's perception of financial incentives } \\
\text { to develop DM program and of WCB's role }\end{array}$ \\
\hline Question 18 & Open-ended & Additional comments about topic \\
\hline
\end{tabular}

The research involved sending the survey out to less than 2,000 CSAM members in total, consisting of electrical, general, mechanical and trade contractors. A link was added to CSAM's homepage and a direct email inviting members to complete the survey was sent out to members two weeks later. The survey was made available electronically for five consecutive weeks, resulting in a total of 88 survey responses received, and thus making for a confidence level of $95 \%$ and a confidence interval of $10 \%$. It was reviewed and approved by the University of Manitoba Research Ethics Board prior to its deployment. 
Descriptive statistics were used to analyze the results, with inferential statistics used in a few instances only to evaluate the statistical significance of some results at $p=0.05$ (95\% level of

confidence). The two nonparametric tests used to analyze survey results include the Spearman's Rank Correlation Coefficient (SRCC) test and the Kruskal-Wallis (KW) test. The SRCC test was used to assess the relationship between: 1) Organizations' total number of employees and percentage of disabled employees in them, 2) Organizations' COR certification and their implementation of a DM program and 3) Organizations' perception of financial incentives aimed at developing or improving DM programs and their implementation of a DM program. The Kruskal-Wallis (KW) test was used to determine if there were statistically significant differences in the: 1) Percentage of disabled employees in different types of organizations (i.e. electrical contractor, general contractor, mechanical contractor, trade contractor), 2) Percentage of disabled employees in organizations doing different types of work (i.e. residential, commercial/ institutional, industrial, heavy/ civil), 3) Disabilities accommodated by different types of organizations and 4) Disabilities accommodated by organizations doing different types of work.

\section{RESEARCH RESULTS AND DISCUSSION}

This section presents the results of the detailed analysis of all survey responses and a discussion of these results within the wider context of the literature. The results and discussion will focus on the demographics of the sample surveyed, the employment status of workers disabled as a result of a workplace injury, and the specific disabilities accommodated by responding construction organizations. The results and discussion will also focus on the implementation of DM programs in the industry, including the rationale behind implementing them, barriers to their implementation and the practices, accommodations and resources used as part of them, and their perception of the literature results. 


\subsection{Demographics}

Of the 88 responding organizations, approximately, $43 \%$ were trade contractors and $34 \%$ were general contractors. Approximately, 56\% of respondents identified themselves as health and safety managers or representatives. Owners and senior managers represented $31 \%$ of all respondents. Approximately, $77 \%$ of them were in organizations with less than 25 employees. This is not unexpected given how owners and senior managers tend to be the ones directly responsible for health and safety in small organizations. Only 3\% of respondents were RTW coordinators or RTW representatives, and belonged to medium-sized organizations with 100 or more employees, reflecting a tendency for larger organizations to hire RTW representatives that are independent from their health and safety representatives. The majority of responding organizations $(80 \%)$ were COR certified.

\subsection{Employment of Disabled Workers}

The analysis of survey responses showed how a large portion of responding organizations (47\%) did not employ workers disabled as a result of a workplace injury. Approximately, $32 \%$ had less than $1 \%$ of these workers within their workforce. Only $4 \%$ employed $5 \%$ or more disabled workers. Statistically, only a moderate, statistically significant correlation $(r=0.359, p=0.003)$ was found between the total number of workers in an organization and the percentage of returning disabled workers employed in each. The research slightly adapted the definitions set by Industry Canada (2014) for the size of construction organizations, with organizations with less than 100 employees considered small, the ones employing between 100 and less than 500 employees considered medium, and the ones with 500 employees or more considered large. Given the size of the Manitoban market, a distinction was made between organizations with less 
than 25 employees, those with 25 but less than 50 employees, and those with 50 but less than 100 employees. Organizations with less than 25 employees had $0.82 \%$ disabled workers, those with 25 to less than 50 employees had $0.96 \%$ disabled workers and those with 50 to less than 100 employees had $1 \%$ disabled workers as a result of workplace injury. Middle-size and large organizations respectively employed $1.27 \%$ and $2 \%$ disabled workers. While these results show that larger organizations in the sample tend to have slightly more disabled workers returning to the workplace than smaller ones, the differences in the percentages of disabled workers employed by organizations of different sizes are very small and statistically insignificant. The expectation was that larger organizations would employ a lot more disabled workers because of their ability to accommodate them more easily than smaller ones.

Electrical and trade contractors employed the smallest percentage of disabled workers at $0.57 \%$ and $0.67 \%$ respectively, with general and mechanical contractors employing a slightly higher percentage of disabled workers at $1.37 \%$ and $2.50 \%$ respectively. The Kruskal-Wallis (KW) test showed no statistically significant difference in any of these values. With respect to the employment of disabled workers by type of work, organizations doing residential work in the sample were found surprisingly to employ only $0.44 \%$ disabled workers whereas organizations doing commercial work employed more disabled workers at $1.04 \%$. This could be due to the smaller size of organizations doing residential work and the fewer work opportunities available to their disabled workers in comparison with organizations doing commercial work. Those doing industrial work were found to employ only $0.54 \%$ disabled workers whereas heavy and civil construction organizations employed $3.75 \%$ disabled workers: the largest percentage of all. Interestingly, statistically significant differences $(H(4)=13.760, p=0.008)$ were found in these percentages, with the Dunn's Bonferroni post hoc test revealing a statistically significant 
difference $(\mathrm{p}=0.023)$ between the $3.80 \%$ disabled workers employed by heavy or civil work construction organizations, and the $0.54 \%$ employed by organizations doing industrial work. These results could be due to the very specialized and sophisticated nature of industrial projects that may make for more challenging physical and mental tasks and thus make it less accommodating to disabled workers than more mainstream heavy and civil construction projects. Heavy and civil construction organizations in the sample also employed on average 100 employees whereas organizations doing industrial work employed 67 employees on average, which may explain the larger number of disabled workers employed in the heavy and civil sector.

\subsection{Disabilities Accommodated}

Table 2 below summarizes respondents' ranking of the most common disabilities found in their organizations and incurred as a result of workplace injuries. Disabilities due to MSI were the most common in the organizations surveyed. This is not surprising since more than half of all time loss injuries in the construction industry are related to MSIs (Workplace Safety and Health Division of Manitoba \& Workers Compensation Board of Manitoba 2007). Physical mobility and hearing impairments came in next, slightly lagging behind musculoskeletal disabilities. Seeing impairments as well as mental disabilities were less common with a large difference in ranking between them and the more common ones.

A more in-depth investigation of the disabilities accommodated by different types of organizations showed how disabilities due to MSI were the most prevalent in workers returning to work for electrical, general, mechanical, and trade contractors. This was followed by disabilities related to physical mobility, except for mechanical contractors who accommodated more people with mental disabilities. With respect to disabilities accommodated by organizations 
doing different types of work, the analysis showed how disability due to MSI was the most common in organizations doing residential and commercial work whereas hearing and physical mobility disabilities were the most common in industrial and heavy and civil construction organizations respectively. Disability due to MSI was found to be the third most common disability in industrial and heavy/ civil construction organizations. The results of the KW test showed no statistically significant differences between the disabilities accommodated by different types of organizations or organizations doing different types of work. This could be due to the fact that construction projects whether industrial, residential, commercial or heavy projects require a minimum amount of physical and mental abilities regardless of the nature of the project. While some projects may require more abilities than others, the differences are so subtle that they do not lead to drastically different results. A larger sample of organizations may uncover different results. Future research should investigate why some disabilities tend to be more common than others.

Table 2: Ranking of Most Common Disabilities Found in Organizations

\begin{tabular}{ccc}
\hline Ranks & Disabilities & Average Rankings* \\
\hline 1 & Musculoskeletal & 6.92 \\
2 & Physical (mobility impairment) & 6.38 \\
3 & Hearing & 6.27 \\
4 & Seeing & 4.65 \\
5 & Mental / Psychological & 4.48 \\
6 & Speaking & 4.31 \\
7 & Disease (cancer, diabetes, etc...) & 4.18 \\
8 & Other & 2.38 \\
\hline *Based on rankings from 1 to 8 by responding organizations, with 1 \\
being the least common disability found in every organization and 8 \\
being the most common one
\end{tabular}




\subsection{Implementation of Disability Management Programs}

Approximately, $62 \%$ of responding organizations implemented a DM program: a level of implementation that reflects an unexpected awareness of the importance of DM programs at the local level among organizations in the sample. This percentage can also be due to sampling bias that may make organizations with a DM program more likely to respond to the questionnaire than ones without one, highlighting the need for research that would avoid this bias. Even though the results of the SRCC test showed a weak, non-statistically significant correlation between COR certification of construction organizations and their implementation of a DM program, $67 \%$ of COR-certified organizations in the sample were found to implement a DM program. This reflects a tendency for organizations with an effective health and safety program in the sample to implement a DM program. This is not surprising given the expectation that organizations with an effective health and safety program would be more likely to have a DM program than organizations without one.

\subsubsection{Rationale behind Implementation of Disability Management Programs An} overwhelming majority of respondents (89\%) in the sample agreed that construction organizations should develop and implement a DM program. Approximately, $81 \%$ of responding organizations that did not have a DM agreed that construction organizations should have one. While those results reflect an awareness of the importance of DM programs among those organizations even when they are not implemented, they could also be the result of sampling bias that would make organizations with a vested interest in the subject more likely to complete the questionnaire than others. Approximately, 56\% of total respondents in the sample saw retaining valued and experienced employees and maintaining employee morale as the main reason for 
doing so. Not surprisingly, smaller organizations with less than 50 employees ranked this reason higher than larger organizations with 50 or more employees. One respondent commented on how retaining workers helped workers feel valued by themselves, their family members and their employers. The second reason perceived by respondents in the sample for why construction organizations should develop and implement a DM program was to reduce costs related to claims, insurance premiums, hiring and training, with larger organizations (100 or more employees) ranking this higher than smaller ones. This is not surprising given how reducing costs is always a priority to construction employers. The two lowest ranked reasons were to comply with existing legislation and enhance an organization's image. Not surprisingly, large organizations with 500 or more employees ranked the need to comply with existing legislation higher than smaller ones. Table 3 summarizes these rankings. Even though $89 \%$ of respondents believed that construction organizations should have a DM program, only $62 \%$ actually implemented them, indicating a discrepancy that requires further investigation.

Table 3: Ranking of Reasons why Organizations should have a Disability Management Program

\begin{tabular}{clcc} 
Ranks & Reasons & & $\begin{array}{c}\text { Average } \\
\text { Rankings* }\end{array}$ \\
\hline 1 & To retain valued and experienced employees and maintain & 4.31 \\
& employee morale & 3.75 \\
3 & To reduce costs (e.g. claims, premiums, hiring and training) & 3.42 \\
4 & To comply with existing legislation & 2.40 \\
\hline
\end{tabular}

*Based on rankings from 1 to 5 by responding organizations, with 1 being the least important reason identified by every organization and 5 being the most important one. The average ranking of the fifth reason: "Other" is not shown in the table. 
4.4.2. Barriers to Implementation of Disability Management Programs Table 4 shows respondents' ranking of the barriers to the successful return of disabled workers following a work injury. Interestingly, the lack of suitable modified or alternate work was found to be the most important barrier. This is not surprising given the physical nature of construction work and thus the limited opportunities for modified or alternate should a physical injury leading to a permanent physical disability occur. One respondent commented on how construction organizations will accommodate injured workers as long as they can do so and that the level of accommodation depended on the seriousness of the injuries sustained. Smaller organizations with less than 50 employees found the lack of suitable modified or alternate work to be more problematic than larger organizations with 50 or employees.

Table 4: Ranking of Barriers to the Return of Disabled Employees back to Work: Statistical Analysis Results

\begin{tabular}{clc}
\hline Ranks & Barriers & Average Rankings \\
\hline 1 & Lack of suitable alternative work & 4.31 \\
2 & Disabled employees motivation & 3.74 \\
3 & Difficulty of communicating with other key parties & 2.89 \\
4 & Cost of accommodation & 2.74 \\
\hline
\end{tabular}

*Based on rankings from 1 to 5 by responding organizations, with 1 being the least important barrier identified by every organization and 5 being the most important one. The average ranking of the fifth barrier: "Other" is not shown in the table.

Disabled employees' motivation was identified as the second most important barrier by the sample of employers surveyed. While this may apply to a larger population of construction employers, it is important to remember that these rankings reflect the subjective opinions of the employers surveyed. Employers may have a tendency to hold workers responsible for not returning once disabled and thus see employee motivation as the main problem. A survey 
administered to workers themselves may see workers shifting the responsibility to employers and thus lead to very different results.

The cost of accommodation was found to be the least important barrier of all. This agrees with Soklaridis et al. (2011) but contradicts Lingard and Saunders (2004) and Kochan et al. (2003) who found cost to be one of the most important barriers to employing disabled or injured workers. This result could also be due to construction employers not wanting to be seen as unwilling to invest in costly accommodations. Although large organizations with 500 or more employees found the cost of accommodation to be more problematic than other smaller organizations, they found cost to be a more important reason for wanting to implement a DM program than smaller organizations.

An investigation of the barriers ranked by organizations implementing a DM program and those that did not implement one shows no difference in the ranking of the barriers proposed. Moreover, the average rankings of every barrier by each of those two categories of organizations are very similar, except for the ranking of the lack of suitable alternate work, and difficulty of communicating with other key parties. Organizations without a DM program found the lack of suitable alternate work to be more problematic than organizations with a DM program, most likely because of how DM programs help define and identify suitable alternate work for disabled workers. Organizations with a DM program found it more difficult on average to communicate with other key parties than organizations without a DM program. This could be due to the communication structure and requirements stipulated by DM programs that may complicate how workplace injuries and return to work cases are communicated and dealt with. 


\subsubsection{Practices Implemented as Part of Disability Management Programs Responding}

organizations with a DM program in place were asked to identify practices used as part of their programs. Approximately, $92 \%$ provided modified or alternate work opportunities to their workers, with all organizations with 25 or more employees providing these opportunities to their workers. This is despite $45 \%$ of organizations providing such work identifying suitable modified or alternate work as the most important barrier to the successful return of disabled workers to the workplace. These somewhat contradictory results may be reflecting the difficulty construction organizations have with providing suitable modified or alternate work that takes real advantage of these workers' skills and abilities. Approximately, 64\% developed customized RTW plans for disabled workers returning to the workplace. This could be due to the limited opportunities for modified or alternate work available to them upon their return that may warrant customized plans. Organizations with 50 or more employees developed these plans more often than smaller ones. Only 58\% and 56\% of all responding organizations developed clear RTW procedures and trained employees on existing programs respectively, with larger organizations (with 50 or more employees) doing this more often than smaller ones. Only $22 \%$ hired a RTW coordinator or established a RTW committee: a result hardly surprising given how the industry predominantly comprises small and medium sized organizations that cannot justify the cost of such investments. The low rate of employment of disabled workers returning to the workplace may also make organizations feel like such investments in personnel are not warranted. The gap in the rate of implementation of that specific practice between small and large organizations was the highest with that rate averaging $63 \%$ for larger organizations with 50 or more employees, and $11 \%$ for smaller ones. Figure 1 shows the percentage of organizations implementing each practice. 


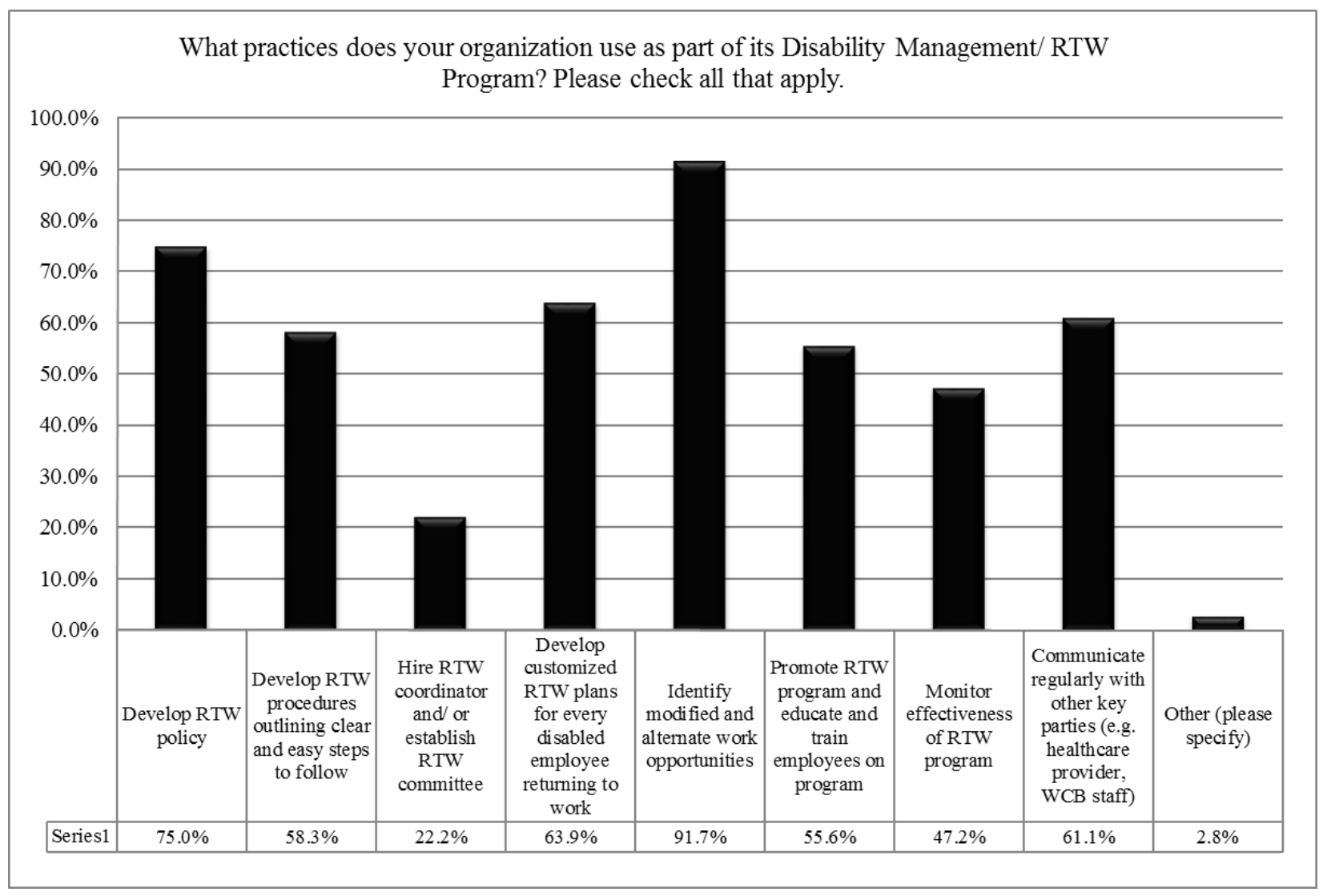

Figure 1: Practices Used by Organizations as part of their Disability Management Programs

4.4.4. Accommodations Provided as Part of Disability Management Programs When asked about the specific accommodations provided to returning disabled workers, $94 \%$ and $83 \%$ of responding organizations chose "modified/ alternate work" and "modified hours/ days" respectively, with no differences in average responses between smaller and larger organizations. These results are in line with the practices identified by responding organizations as part of their DM programs. Only 33\% of responding organizations provided accessible workstations, with $78 \%$ of organizations with 100 or more employees providing those in comparison to $19 \%$ of the smaller ones. Moreover, only $31 \%$ offered accessible washrooms, with $56 \%$ of organizations with 100 or more employees offering those in comparison to $23 \%$ of the smaller ones. Only $11 \%$ provided handrails and ramps and a mere $6 \%$ offered accessible elevators. All of these 
organizations were ones with 50 or more employees, most probably due to the high cost of such accommodations. These results raise concerns about the cost of some accommodations and the ability of smaller organizations to provide them in comparison with larger ones. Figure 2 depicts the percentage of organizations providing each type of accommodation.

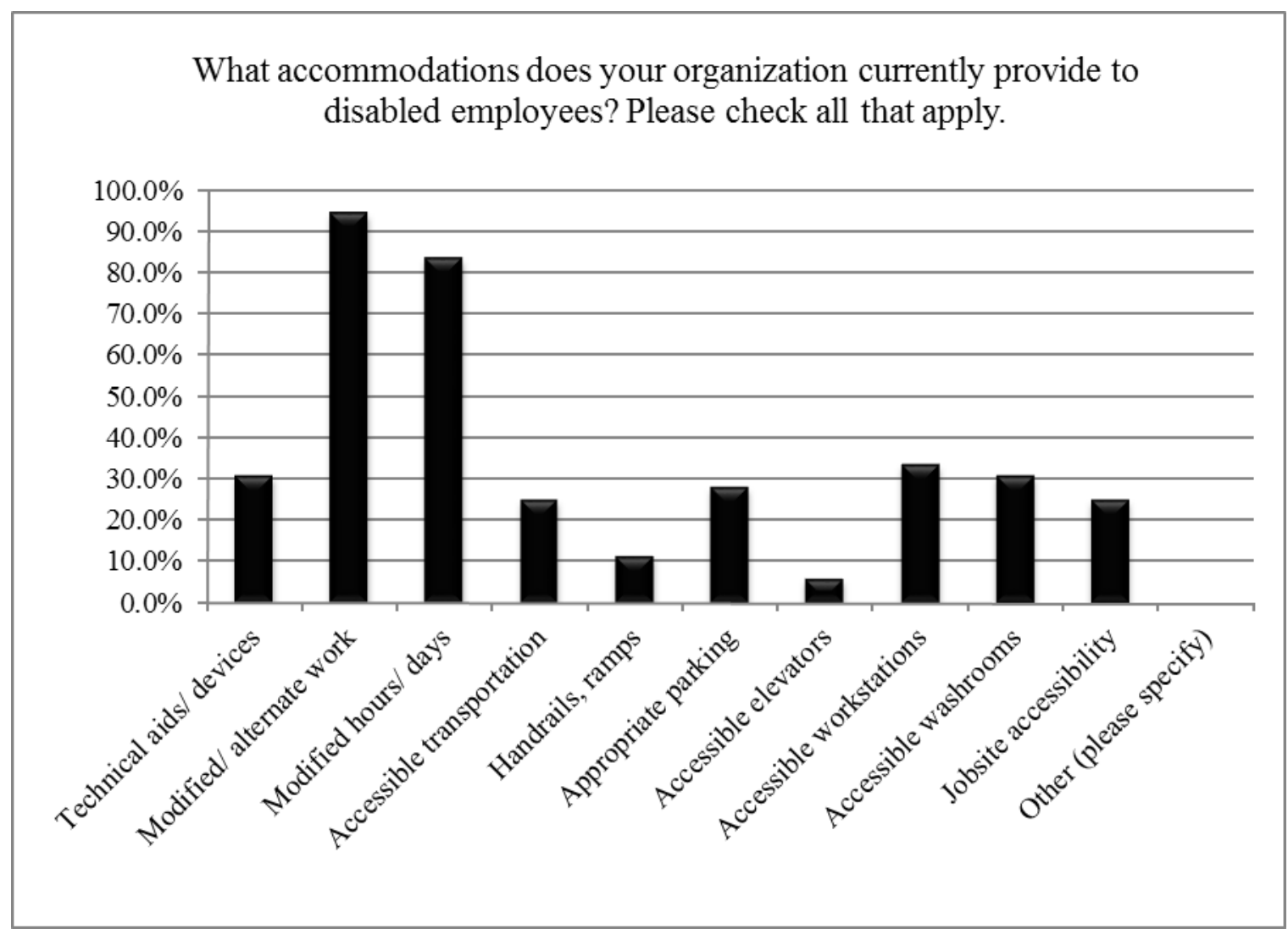

Figure 2: Accommodations Provided by Organizations to Disabled Employees as Part of their Disability Management Programs

4.4.5. Resources Used as Part of Disability Management Programs Approximately, $80 \%$ of responding organizations with a DM program were aware that the WCB can assist them with the planning, coordination and monitoring of their DM programs. All organizations with 100 or more employees were aware of the WCB's role in comparison to $74 \%$ of the companies with less than 
100 employees, reflecting a higher level of awareness among larger companies. Table 5 summarizes the results of their ranking of resources available at their disposal to develop or improve DM programs in terms of their importance. Most organizations seemed to rely on their own internal staff to develop or improve DM programs followed by the WCB. Respondents seemed to communicate frequently with healthcare providers, but less with union representatives, perhaps because of the traditional tense relationship between construction employers and labour unions. Nevertheless, larger organizations seemed to rely more on labour unions than smaller ones, identifying it as the second most important resource after WCB staff. This may be due to the tendency for larger organizations to employ unionized workers in comparison to smaller ones.

Table 5: Accommodations Provided by Organizations to Disabled Employees as Part of their Disability Management Programs

\begin{tabular}{lc}
\hline Accommodations & Responses \\
\hline Modified / alternate work & $94 \%$ \\
Modified hours / days & $83 \%$ \\
Accessible workstations & $33 \%$ \\
Technical aids / devices & $31 \%$ \\
Accessible washrooms & $31 \%$ \\
Appropriate parking & $28 \%$ \\
Jobsite accessibility & $25 \%$ \\
Accessible transportation & $25 \%$ \\
Handrails, ramps & $11 \%$ \\
Accessible elevators & $6 \%$ \\
\hline
\end{tabular}

\subsection{Disability Management Financial Incentives}

A number of financial incentives are available at the federal and provincial levels in Canada for organizations looking to improve accessibility (e.g. Enabling Accessibility Fund and Social Development Fund through Employment and Social Development Canada) (Employment and Social Development Canada 2014). Approximately 60\% of respondents agreed that such incentives would encourage their organizations to develop or improve their DM programs. The 
SRCC test conducted to evaluate the relationship between how construction organizations perceive financial incentives at the federal and provincial levels and whether these organizations had an actual DM program in place showed no statistically significant relationship between these two aspects. Approximately, $70 \%$ of responding organizations without a DM program versus $71 \%$ of those with one felt that financial incentives would encourage them to develop or improve their own DM programs respectively.

\section{CONCLUSIONS AND RECOMMENDATIONS}

This research showed that approximately half of responding construction organizations in Manitoba did not employ workers disabled as a result of a workplace injury, with many organizations engaging less than $1 \%$ disabled workers and a tiny minority engaging $5 \%$ or more disabled workers. No statistically significant difference was found between the percentages of disabled workers employed by larger and smaller organizations. Moreover, more disabled workers were found in organizations doing commercial and heavy and civil work in the sample as opposed to residential and industrial work, and with general and mechanical contractors rather than electrical and trade contractors.

The research also showed how musculoskeletal disabilities were the most common in the organizations surveyed, followed by physical mobility and hearing impairments, with no significant differences in the disabilities accommodated by different types of organizations or organizations doing different work. Future research should focus on investigating why some disabilities tend to be more common than others in the industry and the ones that are more industry-friendly versus the ones that are more difficult to accommodate. 
The research revealed a tendency for COR certified organizations in the sample to implement a DM program. Future research should focus on addressing the lack of empirical evidence relating construction workplace DM to construction safety performance in order to determine whether construction companies that accommodate disabled workers are safer companies to work for. Such research should help make the case for better integrating and accommodating disabled workers in the industry.

The research showed how organizations in the sample saw retaining valued and experienced employees, maintaining employee morale and reducing costs as the most important reasons for implementing a DM program. They also found the lack of suitable work to be the most important barrier to the return of disabled workers, with smaller organizations and organizations without a DM program finding this to be more problematic than larger organizations and organizations with a DM program respectively. This is despite an overwhelming majority of them providing modified or alternate work opportunities to their workers as part of their DM programs. This highlights the need for more detailed assessments of construction jobs to determine the physical and mental skills required for each. It also highlights the need for more detailed assessment of physical and mental disabilities to determine the construction jobs that are most suitable for them and thus the extent to which each disability can be accommodated in the industry.

The research also showed how only a small proportion of responding organizations provided more expensive accommodations to their disabled workers such as accessible washrooms, and accessible workstations, with larger organizations providing those more frequently than smaller ones. This reinforces the need to assess the accessibility of construction workplaces in more detail throughout their entire lifespan to identify the accommodations that are needed to make 
them more accessible. Future research should also investigate the level of maturity and inclusivity of DM practices in construction organizations themselves at the policy and managerial levels.

Future research should focus on surveying a larger sample of construction organizations to improve the confidence level and interval of the results. The 88 organizations surveyed cannot be considered representative of the entire population of construction organizations across Manitoba and as such, the conclusions made about the sample cannot necessarily be generalized to the entire population. Future research should also focus on using a sampling method that does not unintentionally favour one group of respondents over another. The survey sent out to the entire population of CSAM members may have inadvertently led to sampling bias whereby those with a vested interest in the topic or had a positive impression of DM programs would have been more likely to respond, which in turn may have skewed the results. Future research should also clearly define key terms such as "disability", "disabled people" and "disabled workers" and communicate these definitions to survey respondents in order not to leave such terms open to interpretation by them which would skew the results. For example, one organization may consider a "disabled worker" a worker with a physical or mental impairment. A second may consider him or her to be a worker with no physical or mental impairment yet unable to perform a specific work task because of specific health problems (e.g. obesity.

Even though this research identifies the cost of accommodation as the least important barrier to the return of workers with disabilities, there is a need for a more in-depth study of the costs and financial benefits of DM in the industry. Future research should evaluate the start-up costs of developing such programs as well as the longer-term operating and maintenance costs of running 
such programs. It should also investigate the health and productivity benefits of developing and implementing such programs to better assess their cost effectiveness.

Given the focus of this and other research projects on investigating construction employers' perceptions, there is a need to evaluate the perceptions of construction employees themselves. This is essential given how survey responses tend to be contingent on the perceptions of the people surveyed or interviewed. This, in addition to other research initiatives should help challenge the traditional attitude of the construction industry with respect to people with disabilities and thus support the return of injured workers to the workplace once disabled.

\section{ACKNOWLEDGEMENTS}

This research was supported by a grant from the Research and Workplace Innovation Program of the Workers Compensation Board of Manitoba. The authors would also like to thank the Construction Safety Association of Manitoba (CSAM) for help with administering the survey to its members.

\section{REFERENCES}

Association of Workers' Compensation Boards of Canada 2013. Injury statistics [online]. Available from http://awcbc.org/?page_id=14 [accessed 13 June 2014].

Clarke, L., van der Meer, M., Bingham, C., Michielsens, E., \& Miller, S. 2009. Enabling and disabling: disability in the British and Dutch construction sectors. Construction Management and Economics 27(6): 555-566. 
Dainty, A., Bagilhole, B., Ansari, K., \& Jackson, J. 2004. Creating equality in the construction industry: an agenda for change for women and ethnic minorities. Journal of Construction Research 05(01): 75-86.

Employment and Social Development Canada 2014. Disability [online]. Available from http://www.esdc.gc.ca/eng/disability/index.shtml [accessed 7 July 2014].

Galvin, D., Tate, D., and Schwartz, G. 1986. Disability management research: current status, needs and implications for study. Journal of Applied Rehabilitation Counseling 17(3): 4348.

Hursh, N. 1997. Making a difference in the workplace. In W. Zimmerman (Ed.), Strategies for success. Port Alberni, BC: National Institute of Disability Management and Research.

Kochan, T., Bezrukova, K., Ely, R., Jackson, S., Joshi, A., Jehn, K., Leonard, J., Levine, D. and Thomas, D. 2003. The effects of diversity on business performance: report of the diversity research network [online]. Human Resource Management 42(1): 3-21.

Industry Canada 2014. Canadian Industry Statistics (CIS) - Construction (NAICS 23): $\begin{array}{lll}\text { Establishments } & \text { [online]. } & \text { Available }\end{array}$ https://www.ic.gc.ca/app/scr/sbms/sbb/cis/establishments.html?code=23\&lang=eng\%20\%20est2 [accessed 15 February 2014].

Lingard, H., and Saunders, A. 2004. Occupational rehabilitation in the construction industry of Victoria. Construction Management \& Economics 22(10): 1091-1101.

Newton, R., and Ormerod, M. 2005. Do disabled people have a place in the UK construction industry? Construction Management \& Economics 23(10), 1071-1081.

Organization for Economic Cooperation and Development 2010. Sickness, disability and work: breaking the barriers [online]. 
Ormerod, M., and Newton, R. 2006. Embracing diversity through the employment of disabled people. In A. W. Gale \& M. Davidson (Eds.), Managing Diversity and Equality in Construction: initiatives and practice. London; New York: Taylor \& Francis.

Ormerod, M., and Newton, R. 2013. Construction as a career choice for young disabled people: dispelling the myths. Construction Management and Economics 31(8): 928-938.

Rosenthal, D., Hursh, N., Lui, J., Isom, R., and Sasson, J. 2007. A survey of current disability management practice: Emerging trends and implications for certification. Rehabilitation

Counseling Bulletin 50(1): 76-86.

Rosenthal, D., Hursh, N., Lui, J., Zimmerman, W., and Pruett, S. 2005. Case management issues within employer-based disability management. In: F. Chan, M. Leahy, and J. Saunders (Eds.), Case Management for Rehabilitation Health Professionals. Lake Osage, MO: Aspen Professional Services, 1: 330-365.

Shrey, D. and Hursh, N. 1999. Workplace disability management: international trends and perspective. Journal of Occupational Rehabilitation 9(1): 45-59.

Smallwood, J.J. and Haupt, T. 2008. Persons with Disabilities: an Underutilized Construction Resource! In: Jimmie, H., Suezann, B., and Jeffrey, L. (Eds.), Evolutions of and Directions in Construction Safety and Health. 1: 737-751.

Soklaridis, S., Cassidy, J., Van der Velde, G., Tompa, E., and Hogg-Johnson, S. 2011. The economic cost of return to work: an employer's perspective. Work, 43(3): 255-262.

Treasury Board of Canada Secretariat 2011a. The fundamentals - return-to-work plan [online]. Available from http://www.tbs-sct.gc.ca/psm-fpfm/ve/dee/dmi-igi/fun-fon/rtwp-prteng.asp [accessed 1 July 2014]. 
Treasury Board of Canada Secretariat 2011b. What is disability management [online]? Available from $\quad$ http://www.tbs-sct.gc.ca/hrh/dmi-igi/fundamentals-fondements/intro-eng.asp [accessed 1 July 2014].

Tshobotlwane, D. M. 2005. An investigation of the potential role of physically challenged persons in construction. Master of Technology thesis, Cape Peninsula University of Technology, Cape Town, South Africa.

Workers Compensation Board of Manitoba 2000. Modified and Alternate Return to Work with the Accident Employer [online]. Available from http://www.wcb.mb.ca/sites/default/files/files/43_20_20ModifiedAlternateReturntoWork. pdf [accessed 18 June 2014].

Workers Compensation Board of Manitoba, and Workplace Safety and Health Division of Manitoba Labour and Immigration 2013. The Manitoba workplace injury statistics report 2000-2012 [online]. $\quad$ Available from https://safemanitoba.com/sites/default/files/resources/wcb_injury_stats_report_2000_201 2_web.pdf [accessed 18 June 2014].

Workplace Safety and Health Division of Manitoba, and Workers Compensation Board of Manitoba 2007. Illnesses and injuries in the Manitoba construction sector 2000-2005 [online]. $\quad$ Available from http://digitalcollection.gov.mb.ca/awweb/pdfopener?smd=1\&did=19404\&md=1 [accessed 15 June 2014].

World Health Organization 2014. Disabilities [online]. Available from http://www.who.int/topics/disabilities/en/ [accessed 1 July 2014]. 